Marko Kržan

\title{
Znanstveni predmet sociologije kulture
}

Ključne besede: sociologija kulture, marksizem, ideologija, produkcijski način

\section{Predmet razprave in pregled argumentacije}

V razpravi poskušamo sociologijo kulture formalno izpeljati iz marksistične obče sociologije. Rezultat izpeljave je opredelitev metode in znanstvenega, raziskovalnega predmeta sociologije kulture. Raziskovalnega predmeta $\mathrm{v}$ tem pomenu seveda ne smemo mešatiz raziskovalnim projektom ali programsko skupino kot institucionalnima oblikama raziskovalnih skupin, pa tudi ne z učnim načrtom kake konkretne katedre ali oddelka. Kljub temu se bo pokazalo, da je tukajšnja izpeljava zgolj rezultat razvijanja zastavitve, katere korenine na Oddelku za sociologijo Filozofske fakultete Univerze v Ljubljani segajo že v sedemdeseta leta 20. stoletja.

Izhodišče, ki ga obravnavamo $\mathrm{v}$ drugem razdelku, sta dve mogoči opredelitvi predmeta sociologije kulture. Prva možnost je, da za znanstveni predlog vzamemo empirični predmet »kultura«, druga pa, da vse družbene pojave obravnavamo kot pojave, ki poleg objektivne razsežnosti družbene strukture vključujejo tudi "predstavo«, ki jo imajo o tej strukturi družbeni akterji. Dilemo bomo poskusili rešiti v treh korakih. Prvi korak bo opredelitev osnovne epistemološke predpostavke sleherne sociologije, totalnega družbenega dejstva.

V tretjem razdelku bomo pokazali, da nekaterih družbenih praks ni mogoče pojasniti zgolj z uporabo koncepta totalnega družbenega dejstva. Tovrstne prakse imajo sicer same po sebi prav tako strukturo praksa plus predstava. Toda njihova specifika je v podvojitvi totalnega družbenega dejstva. Po eni strani so te prakse same táko družbeno dejstvo (praksa in predstava), hkrati pa so tudi del širšega družbenega dejstva, v katerem funkcionirajo kot predstava. Za zgled spoznavne (ideološke) prakse v nasprotju z materialno (ekonomsko) prakso bomo, sledeč Kerševanu, vzeli primer religiozne prakse. Tudi ta je sama po sebi sklop prakse in predstave, ki to prakso omogoča, hkrati pa kot celota proizvaja (ideološke) učinke, ki se nanašajo na druge, materialne prakse.

Četrti razdelek obravnava zadnji korak izpeljave predmeta sociologije kulture. Iz prvih dveh izhaja, da gre za vedo, ki proučuje prakse, pri katerih pride do podvojitve 
totalnega družbenega dejstva, torej spoznavne prakse. Tretji korak pa nam omogoči, da $\mathrm{v}$ konceptu upoštevamo vse posledice zgornje zastavitve. Ideološke prakse so dvojno določene, po eni strani so družbene prakse kakor vse druge, hkrati pa so še v posebnem razmerju do materialnih praks. Prva določitev, ki zadeva notranjo strukturo ideološke prakse, je »formalna «, druga, ki zadeva njeno razmerje do drugih praks, pa »vsebinska«. V modernih družbah se pogosto dogaja, da se spoznavna praksa po notranji strukturi ne razlikuje od neideoloških, ekonomskih praks. Množična kultura, recimo, je na Zahodu tržna dejavnost kot vsaka druga. Toda dejstvo, da je notranje organizirana kot (tržna) ekonomska praksa, še ne pomeni, da nima specifično ideološkega učinka v razmerju do drugih praks. Sociologija kulture mora proučevati tako notranjo organizacijo kot družbene učinke spoznavnih praks, tj. oblik družbene zavesti.

$\mathrm{V}$ zadnjem razdelku je kratek povzetek $\mathrm{z}$ nekaj opombami za nadaljnje raziskovanje.

\section{Totalno družbeno dejstvo kot epistemološka podlaga obče sociologije in sociologije kulture}

Na prvi pogled se zdi, da lahko raziskovalni program sociologije kulture opredelimo na dva načina. Lahko izhajamo iz empiričnega predmeta raziskovanja in trdimo, da je sociologija kulture področna sociologija, ki raziskuje t. i. kulturne pojave (umetnost, popularno kulturo ...), skratka »oblike družbene zavesti«. Lahko pa jo opredelimo kot poseben tip obče sociologije, ki izhaja iz aksioma, da so pojavi v družbi kulturno konstruirani, da je družba torej skupek praks, ki jih ljudje opravljajo $\mathrm{z}$ »zavestjo«, torej $\mathrm{z}$ določeno vednostjo, predstavo. $\mathrm{V}$ tem primeru je sociologija kulture oznaka za določen pristop, metodo v sociologiji nasploh ( $\mathrm{tj}$. njeno temeljno epistemološko naravnanost).

Navidezno nasprotje med tema možnostma lahko razreši dialektična sinteza, ki po eni strani izlušči, kar je v obeh zastavitvah pravilnega, po drugi strani pa odpravi napaki, ki nas ovirata, da bi iz intuitivnih opredelitev prišli do znanstvene opredelitve predmeta. Druga zastavitev ima prav, ko trdi, da so vsi družbeni pojavi strukturirani kot predmet in predstava, a se moti, ker ne vidi, da na različnih družbenih instancah ta temeljna struktura deluje različno. Prva zastavitev pravilno izpostavi specifiko kulture kot posebne družbene instance, a te specifike ne more definirati. Ker ne pozna temeljne strukture družbenega dejstva, tudi ne more določiti tistih dodatnih določitev, ki iz njega napravijo »kulturno« oziroma spoznavno (ideološko) družbeno dejstvo.

Če hočemo to napako odpraviti, moramo torej izhajati iz splošne opredelitve družbenega dejstva kot pojava $\mathrm{z}$ dvema poloma. Po eni strani je družbeno dejstvo 
sklop družbenih razmerij, ki jih je mogoče proučevati kot objektivno strukturo oziroma stvar ali reč. Toda ta struktura je le ena, statična plat družbenega dejstva. Ker je družbeno dejstvo praksa, v kateri delujejo družbeno konstituirani agenti (posamezniki, skupine, institucije), lahko zares obstaja (poteka in se reproducira) samo prek aktivnega delovanja teh agentov, za delovanje pa ti agenti potrebujejo določeno vednost, predstavo o razmerjih samih, ta predstava pa je vtkana v njihov habitus.

Pozornima bralki in bralcu seveda ne bo ušlo, da uporabljamo tri pare izrazov, ki napeljujejo na tri velike znanstvenike - Durkheima (stvar - predstava), Marxa (razmerja/praksa - zavest) in Bourdieuja (struktura - habitus). Klasično formulacijo »francoske« (strukturalistične) smeri, ki vodi od Durkheima prek Maussa do Bourdieuja, najdemo pri Lévi-Straussu (1996, 243-244): »Posebni položaj [...] družbenih znanosti izhaja iz notranje narave njihovega predmeta, ki je v tem, da je hkrati objekt in subjekt ali, če se izrazimo v govorici Durkheima in Maussa, »stvar in reprezentacija«. [...] Če hočemo ustrezno doumeti družbeno dejstvo, tedaj ga moramo doumeti totalno, se pravi od zunaj kot stvar, a kot stvar, katere neločljiv sestavni del je subjektivni (zavestni ali nezavedni) dojem, ki bi ga o njem imeli [...], če bi to dejstvo opazovali kot domačini[.]»

$\mathrm{Tu}$ se ne bomo spuščali $\mathrm{v}$ podrobnosti te zastavitve, ${ }^{1}$ ki vsekakor presega strukturalistično in marksistično paradigmo. Spomnimo naj samo na Mertonovo $(1968,511)$ ugotovitev, da je ločevanje med objektivno eksistencialno bazo in vednostjo ter raziskovanje njune povezanosti (v smislu odražanja, ujemanja, izražanja) temeljni postulat vsakršne sociologije vednosti. Ker sociologija vednosti pri socioloških klasikih ni proučevanje kake posebne družbene sfere, ampak vloge vednosti $\mathrm{v}$ družbenem delovanju nasploh, gre za enega temeljnih postulatov obče sociologije. Obča sociologija je podlaga sociologije kulture najprej zato, ker ji priskrbi temeljno epistemološko vodilo, koncept totalnega družbenega dejstva.

\section{Podvojitev družbenega dejstva. »Spoznavna praksa « kot predmet sociologije kulture}

Nakazano občesociološko zastavitev bomo zdaj razvijali v okviru marksistične teorije. Nemarksistične teorije namreč niso naredile drugega in tretjega koraka, brez katerih po našem mnenju ni opredelitve predmeta sociologije kulture. V tem razdelku moramo pojasniti razliko med dvema definicijama ideologije. Ena je namreč univerzalna, ker velja za vsako totalno družbeno dejstvo, druga pa je ožja in velja samo za tista totalna družbena dejstva, ki so predmet sociologije kulture. 
Ločevanje med dvema vrstama ideologije sta Marx in Engels vpeljala v Nemški ideologiji. Po eni strani je ideologija praktična zavest, znameniti »jezik vsakdanjega življenja« (Marx, Engels, 1979, 35). Gre torej za zavest, ki je neločljiv moment vsakega družbenega dejstva oziroma prakse, kajti, kot zapiše Althusser $(2000,95)$ : »[S]leherna praksa je mogoča samo prek kakšne ideologije in v njej[.] « Po drugi strani pa sta Marx in Engels ideologijo opredelila tudi precej ožje, kot področje »čiste teorije« (Marx, Engels, 1979, 37) oziroma »družbenih form zavesti« (Marx, 1989, 90). Ta opredelitev, ki se je v SZ-ju razvila v pojem ideoloških nadzidav in se je uporabljala za vse, kar spontano razumemo pod imenom kultura (religija, morala, filozofija, umetnost, znanost), je primerno izhodišče za nadaljnjo razpravo. ${ }^{2}$

Problem razlikovanja teh dveh vrst pojavov je rešil Marko Kerševan (1975, 62-66, 69-70, 117-123). Rešitev lahko v grobem povzamemo takole: obstajata vsaj dve vrsti družbenih praks (dejstev). Nekatere, imenovane materialne, delujejo neposredno na realnem predmetu (človekovem naravnem in družbenem okolju), ki ga preoblikujejo $\mathrm{z}$ uporabo produkcijskih sredstev. Ljudje, ki so vključeni $\mathrm{v}$ to prakso, stopajo $\mathrm{v}$ produkcijska razmerja, ki določajo, kdo in kako bo razpolagal s produkcijskimi sredstvi (in produkti) dane prakse. Zgled je lahko ekonomska praksa kot sklop proizvodnje, cirkulacije in distribucije predmetov. Druga vrsta prakse, spoznavna, je sicer prav tako usmerjena na določen realni predmet (človekovo naravno in družbeno okolje), toda tega predmeta ne spreminja neposredno, ampak tako, da obdeluje določen miselni, spoznavni predmet, s čimer preoblikuje zavest družbenih agentov o njihovem naravnem in družbenem okolju (realnem predmetu). Pri obdelovanju tega spoznavnega predmeta stopajo ljudje v družbene odnose, ki določajo, kdo ter kako razpolaga in dostopa do produkcijskih sredstev in produkta dane prakse (torej do spoznavnega predmeta).

Vsaka praksa, tudi materialna, je sklop družbenih razmerij, ki se realizirajo le skozi delovanje ljudi, torej v določeni ideologiji in prek nje. Posebnost spoznavnih praks je v podvojitvi ideologije. Po eni strani je tu ideologija, prek katere in v kateri delujejo ljudje, ki so udeleženci spoznavne prakse. Recimo ji praktična zavest spoznavne prakse. Po drugi strani pa je produkt spoznavne prakse poleg praktične zavesti in neodvisno od nje še določen ideološki predmet (in učinek), ki je ena od ideologij v ožjem pomenu oziroma ena od oblik družbene zavesti. Tega razcepa pri materialnih praksah ni.

Za zgled spoznavne ali ideološke prakse lahko vzamemo religiozno prakso. Opisano dvojnost opazimo že na ravni kakega obreda, recimo krščanske evharistije. Po eni strani gre za niz gest in izjav, ki jih s pomočjo pripomočkov, kot so hostija, oltar in

2 Za natančnejšo obravnavo definicij ideologije prim.: Williams (1975, 55-56). 
obredno posodje, izvajajo duhovnik in verniki. Pri tem stopajo v družbena razmerja, ki natančno določajo njihove vloge v obredu. Obred je mogoč zaradi vednosti, ki jo imajo udeleženci o teh razmerjih in o izvedbi obreda. Toda po drugi strani so obredni pripomočki in izreki del religioznega predmeta, ki se nanaša na realni predmet. Ne da bi se spuščali v podrobnosti, lahko s Kerševanom $(1975,70)$ rečemo, da gre pri realnem predmetu za tiste vidike družbenega in naravnega okolja, ki si jih ljudje ne zmorejo prisvojiti z drugimi (spoznavnimi) praksami, recimo jim »zadnja vprašanja» človeškega bivanja.

Če se odmaknemo od ozkega obreda in religiozno prakso obravnavamo kot celoto, lahko torej vidimo, da je religiozna praksa sama po sebi sklop družbenih razmerij, ki določajo, kdo in kako razpolaga $\mathrm{z}$ religioznim predmetom. V najširšem smislu gre za to, katera družbena skupina ima monopol nad razvijanjem doktrine, izvajanjem obredja, kako globok je ta monopol (tj. kolikšna je vloga »laikov«) in kako odprt je (kdo se lahko prebije med posvečene). Temu sklopu družbenih razmerij ustreza določena oblika praktične zavesti, ki ne obsega le tehnične vednosti za izvajanje obredja in delovanje $\mathrm{v}$ verski skupnosti, ampak se razvije $\mathrm{v}$ "posebno skupinsko ideologijo« (Kerševan, 1975, 123). Ta ideologija posvečuje neenakosti, ki izhajajo iz strukture razmerij znotraj religiozne prakse (sfere), prav ta notranja struktura pa je po mnenju nekaterih vplivnih proučevalcev glavni predmet sociologije religije (Kerševan, $1975,117) .^{3}$

Hkrati pa se religiozna praksa nanaša na družbeno in naravno okolje, ki je zunaj njenega religioznega predmeta (realni predmet), s tem ko proizvaja specifično religiozno ideologijo, katere učinek je vpliv na zavest ljudi o tem družbenem in naravnem okolju. Ima torej specifično ideološki učinek legitimacije, kompenzacije itn. družbenih razmerij, ki niso istovetna z notranjimi religioznimi razmerji. Ta razsežnost religije je včasih opredeljena kot predmet ločene discipline, (obče) religiologije (Kerševan, 1975, 117).

V Maussovem žargonu lahko torej rečemo, da je religija hkrati posebno totalno družbeno dejstvo (notranja religiozna razmerja in njim ustrezajoča praktična zavest) ter predstavni del širšega družbenega dejstva, družbene formacije v celoti (kajti ta je realni predmet, na katerega se religiozna ideologija nanaša). ${ }^{4}$ To nam zadostuje za minimalno opredelitev predmeta sociologije kulture. Sociologija kulture proučuje t. i. spoznavne prakse, torej prakse s specifično ideološkimi učinki. Proučuje tako njihovo notranjo strukturo (ideološko prakso kot totalno družbeno dejstvo) kakor

3 Prim. Troeltschevo in Webrovo klasifikacijo organizacijskih oblik religioznih skupnosti, kot so cerkev, denominacija, sekta itn.

4 To je drugi, bolj trivialni pomen Maussove opredelitve totalnega družbenega dejstva: družba, vzeta kot celota, je totalno družbeno dejstvo zato, ker je hkrati ekonomski, politični in ideološki pojav. 
tudi njihovo vlogo v celotni družbeni strukturi (kot "predstava «, ki je del širšega totalnega družbenega dejstva).

\section{$4 \quad$ Vsebinska in formalna določitev predmeta sociologije kulture}

Že na prvi pogled je jasno, da naše razlikovanje materialnih in spoznavnih praks bolj ali manj ustreza Marxovi topiki baze in nadzidave. Nekateri kritiki (Parsons, 1964, 23-24) so ugotavljali, da si marksisti bazo predstavljajo brez zavesti, ki naj bi jo v celoti prenesli v nadzidavo in izenačili z ideologijo. A iz zgornje zastavitve jasno izhaja, da so tudi prakse v bazi mogoče le v kaki ideologiji (praktični zavesti) in prek nje, da pa ideologijo $\mathrm{v}$ ožjem pomenu proizvajajo le tiste prakse, ki so del nadzidave (družbene oblike zavesti).

Pravi problem te koncepcije je torej drugje. Delitev družbenih sfer na tiste, ki pripadajo bazi, in one, ki jih je treba uvrstiti v nadzidavo, je vse prej kot preprosta. Kot je pokazal Kerševan (1980, 67-68), se je v marksizmu oblikovala vrsta kriterijev, ki naj bi jih pri tem uporabili. Vse je mogoče grobo uvrstiti v dve široki kategoriji, med »vsebinske« in »formalne«.

Vsebinski kriteriji zadevajo predmet kake prakse, navadno naj bi v bazo spadale prakse $\mathrm{z}$ materialnim predmetom, $\mathrm{v}$ nadzidavo pa tiste $\mathrm{z}$ duhovnim. Dualizem duha in materije je sicer sam po sebi problematičen, vendar se mu ni mogoče izogniti. Kerševanova opredelitev spoznavnih praks nazorno dokazuje, da je mogoče izdelati soliden kriterij, ki se izogne filozofskim aporijam: določeno družbeno prakso bomo razvrstili glede na to, kako učinkuje na druge družbene prakse (in družbo kot celoto). Če nanje učinkuje neposredno v svoji materialni razsežnosti, spada med materialne prakse. Če pa ima še drugo razsežnost, torej specifično ideološki produkt in učinek, ki je razmeroma neodvisen od materialnih nosilcev njenega spoznavnega predmeta, spada med spoznavne prakse. ${ }^{5}$

5 Sposobnost ločevanja med dvema oblikama vzročnosti, ki sta predpostavljeni v tej delitvi, ločuje dialektični materializem od mehaničnega. Mehanični dopušča le linearno vzročnost: produkcijske sile v bazi vplivajo na materialni nosilec ideoloških praks (v kameni dobi človek ni mogel klesati kipov s pnevmatskim kladivom), produkcijski odnosi v bazi na način organizacije umetnostne dejavnosti (v arhaični družbi ne more biti tržno organizirane umetnostne produkcije), praktična zavest materialnih praks pa na družbene oblike zavesti (od tod različne teorije reifikacije). Dialektični materializem teh povezav sicer ne zanika, vendar pa poleg njih pozna še strukturno vzročnost, pri kateri se spoznavna praksa kot celota, s svojim specifično ideološkim učinkom, odziva na celotno strukturo materialnih praks (baze) in nanje vzvratno vpliva. Razliko med mehaničnim in dialektičnim materializmom sem na podlagi Althusserjeve teorije vzročnosti na primeru Buharina in Vološinova razvijal v: Kržan (2008, 244-245). 
Formalni kriterij zadeva obliko družbenih odnosov znotraj določene prakse. Ta klasifikacija temelji na predpostavki, da baza in nadzidava nista transhistorična pojava, ampak vselej baza ali nadzidava določenega, zgodovinsko specifičnega produkcijskega načina $(\mathrm{PN})$. V bazo spadajo prakse, ki so neposredno udeležene $\mathrm{v}$ ekonomski reprodukciji danega $\mathrm{PN}$-ja, v nadzidavo pa prakse, ki so neposredno udeležene pri reprodukciji njegove politične in ideološke instance. Indikator te »udeleženosti« je oblika družbenih razmerij: formalno gledano sta $\mathrm{v}$ kapitalističnem produkcijskem načinu (KPN) tako proizvodnja klavirja kot poustvarjanje klavirske glasbe, če je ta organizirana po tržnem načelu, del baze, čeprav je izvajanje glasbe kot del umetnosti vsebinsko gledano spoznavna praksa, proizvodnja glasbil pa materialna.

Marksistična sociologija mora pri vseh svojih osrednjih kategorijah uporabljati oba kriterija. V tem se razlikuje od, na primer, neoklasične ekonomije, ki za opredeljevanje ekonomskih dejstev uporablja zgolj formalni kriterij. Glede na to, ali je ta kriterij vrsta družbenega delovanja (smotrno-racionalno delovanje) ali pa kar oblika ekonomske organizacije (blagovni odnos), je definicija ali preširoka ali pa preozka. Smotrno-racionalno delovanje namreč poznamo tudi v politiki, vojaški strategiji, na področju tehnologije (Parsons, 1964, 77), medtem ko je blagovna oblika gospodarstva v zgodovini bolj izjema kot pravilo. Formalno opredelitev ekonomske prakse je treba zato $\mathrm{v}$ historičnem materializmu dopolniti $\mathrm{z}$ vsebinsko, npr. $\mathrm{v}$ smislu produkcije, cirkulacije in distribucije dobrin (Godelier, 1972, 251-257).

Najslikovitejši zgled hkratne uporabe obeh kriterijev je Marxova zavrnitev nekega kritika $^{6}$ v Kapitalu:

O mojem nazoru, da so določeni način produkcije in njemu vsakokrat ustrezajoči produkcijski odnosi, skratka »ekonomska struktura družbe realna baza, na kateri se dviga juridična in politična nadstavba in kateri ustrezajo določene družbene oblike zavesti « [...] - o tem nazoru je dejal, da je sicer vse to pravilno za današnji svet, kjer vladajo materialni interesi, da pa ne velja niti za srednji vek, ko je vladal katolicizem, niti za Atene in Rim, kjer je vladala politika. [...] Toliko je jasno, da srednji vek ni mogel živeti od katolicizma in antični svet ne od politike. Obratno pa nam način, kako so si pridobivali za življenje, pove, zakaj je tam imela politika, a tu katolicizem glavno vlogo (Marx, 1986, 81).

Pozneje je Althusserjeva šola na tej podlagi razvila razlikovanje med determinanto in dominanto (Kerševan, 1980, 83). Determinanta je vselej ekonomija, opredeljena vsebinsko (pridobivanje, cirkulacija ter distribucija produkcijskih in življenjskih sredstev). Oblika ekonomske organizacije (način pridobivanja) pa določa dominantno

6 Podobno kritiko najdemo pri Maxu Schelerju, prim.: Merton (1968, 518-519). 
instanco v PN-ju, znotraj katere se praktično artikulirajo razredna protislovja in ki praktično organizira celotno družbeno življenje. Ekonomska podlaga produkcije $\mathrm{v}$ antiki je bila zemljiška lastnina, alokacija zemlje in dela pa ni potekala v okviru trga kot danes, temveč s političnimi sredstvi. Politika je bila dominantna instanca zato, ker so bila politična sredstva odločilna za organizacijo ekonomskega življenja. V KPN-ju je ekonomija hkrati determinanta in dominanta zato, ker o alokaciji faktorjev odločajo trgi, torej imanentno ekonomske institucije.

Iz razlike med dominanto in determinanto je treba izpeljati še eno razliko med pristopom obče sociologije in marksistične ekonomije na eni strani ter sociologije kulture na drugi. Začnemo lahko s hipotezo, da so družbena razmerja v dominantni družbeni instanci odločilna za materialno reprodukcijo družbe. To pa pomeni, da se specifična oblika, ki jo privzamejo v »matični« instanci, »vsiljuje« tudi preostalima instancama. Imperializem politične forme $\mathrm{v}$ antični ekonomiji smo že omenili. A za nas je zanimivejši imperializem ekonomske, blagovne forme v kapitalizmu. Tu namreč ne gre le za to, da trgi organizirajo ekonomsko dejavnost (ker se pač dominanta ujema $\mathrm{z}$ determinanto), ampak da se blagovna forma vsiljuje tudi drugima instancama, bodisi kot neposredna oblika organiziranja njunih notranjih odnosov bodisi kot nezavedni smoter njune imanentne prakse. Očiten primer prvega je komercialna kultura (umetnost, znanost, šolstvo), primer drugega pa, recimo, politični sistem parlamentarizma, ki v svoji materialnosti preprečuje, da bi se razredni boj politično artikuliral (Althusser, 2000, 120).

Sociologija kulture se pri proučevanju družbenih oblik zavesti v kapitalizmu srečuje s paradoksom, da se lahko določena spoznavna praksa $\mathrm{z}$ vidika dominante (formalnega kriterija), torej po svoji notranji organiziranosti, uvršča v bazo, z vidika determinante (vsebinsko, po svoji osnovni funkciji) pa v nadzidavo. To je posledica dejstva, da družbene oblike zavesti nikoli niso determinanta, epistemološka posledica pa je, da je treba takšne pojave proučevati dvojno, zdaj kot ideološke, zdaj kot ekonomske pojave, torej kot bazo ali nadzidavo istega $\mathrm{PN}$-ja.

Pri pojavih, ki jih uvrščamo v bazo, pa pristop ni simetričen. Mogoče si je zamisliti celo vrsto spoznavnih praks, ki s stališča vsebinskega kriterija spadajo $\mathrm{v}$ nadzidavo, vendar jih je treba ob upoštevanju formalnega kriterija zaradi njihove notranje organiziranosti obravnavati tudi kot del baze tega PN-ja. Primer so že večkrat omenjene oblike komercialne kulture. Če bi, hipotetično, obstajala striktno tržno organizirana religija, bi imeli predmet empiričnega raziskovanja dveh ved, od katerih bi ena (religiologija) proučevala ideološke učinke, druga (sociologija religije) pa družbenoekonomske zakonitosti dane religije. To je mogoče zaradi relativne avtonomije teh dveh momentov spoznavne družbene prakse. 
Nasprotno pa moramo družbeno prakso, ki je po vsebinskem kriteriju del baze (produkcije), po formalnem pa ne, vselej uvrstiti v drug, ločen PN. Ta pristop je Marx uporabil pri konceptu produktivnega dela. Formalna določitev produktivnega dela v KPN-ju je, da je organizirano v okviru kapitalističnega trga dela, kot mezdno delo. Drugi, vsebinski kriterij pa določa, da je produktivno le mezdno delo, ki je porabljeno v produkciji (posebni sferi materialne reprodukcije), ne pa v cirkulaciji ali distribuciji blaga in tržnih storitev (Shaikh, Tonak, 1994, 29). Za zgled lahko kot Marx $(1986,460)$ vzamemo proizvajalca klobas in učitelja, mezdna delavca v institucijah (tovarni in šoli), ki za profit prodajata svoje storitve. Šolo moramo proučevati zdaj kot del nadzidave (ideološki aparat), zdaj kot bazo (tržni subjekt). Za uvrstitev v bazo zadostuje ugotovitev, da je šola del trga, učiteljevo delo pa štejemo za produktivno, ker to tržno storitev proizvaja, ne pa, recimo, oglašuje ali trži. Iz tega lahko izpeljemo preprost napotek: pri uvrščanju družbenih praks v bazo najprej upoštevamo formalni kriterij.

PN v svoji bazi ne trpi družbenih praks, ki ne bi bile organizirane v obliki njegovih temeljnih produkcijskih razmerij, $\mathrm{v}$ nadzidavi pač. To pa pomeni, da smo z ločitvijo materialnih in nematerialnih praks ter vsebinskega in formalnega kriterija mimogrede proizvedli tudi kriterij, na podlagi katerega se lahko odločimo, ali določeno prakso uvrstiti v dani PN ali pa jo proučevati kot del drugega PN-ja znotraj iste družbene formacije. Pri ekonomskih praksah je ta postopek razmeroma preprost, ker moramo izločiti vse ekonomske prakse, ki niso organizirane v obliki produkcijskih razmerij, ki po definiciji pripadajo danemu PN-ju. Pri spoznavnih praksah pa mora biti »vsebinska« opredelitev dovolj bogata, da lahko iz nje razberemo, ali določena praksa sodeluje pri reprodukciji nadzidave - in s tem zunajekonomskih pogojev temeljnih produkcijskih razmerij določenega $\mathrm{PN}$-ja - ali ne.

\section{$5 \quad$ Sklep}

V razpravi smo izhajali iz dveh intuitivnih možnosti za izbiro predmeta sociologije kulture. S pomočjo dialektične sinteze smo prišli do naslednjih rezultatov:

1. Za izhodišče je treba vzeti totalno družbeno dejstvo, to je epistemološko vodilo, po katerem je vsaka praksa sestavljena iz strukture in praktične zavesti (ideologije $\mathrm{v}$ širšem pomenu). V tem smislu je treba izhajati iz metodološke opredelitve predmeta sociologije kulture.

2. Nato moramo v koncepcijo vključiti tista družbena dejstva, ki so sama po sebi taka totalna družbena dejstva, hkrati pa strukturno delujejo kot predstava (ideologija) $\mathrm{v}$ razmerju do drugih totalnih družbenih dejstev, ki te podvojitve ne poznajo. To so spoznavne prakse ali oblike družbene zavesti, ki so predmet sociologije kulture. 
Empirična opredelitev tej definiciji ustreza zato, ker v KPN-ju družbene instance obstajajo kot relativno ločene sfere - pojav, ki nikakor ni univerzalen in ga je tudi v KPN-ju treba pojasniti.

3. Materialnih in spoznavnih praks ne moremo na enak način klasificirati kot elemente baze in nadzidave. Pri materialnih praksah je odločilen formalni kriterij, tj. ali so organizirane v obliki produkcijskih razmerij, ki prevladujejo v danem PNju. Pri spoznavnih praksah formalni kriterij ni odločilen, zato mora biti vsebinska opredelitev dovolj bogata, da je mogoče dano prakso zgolj na njeni podlagi uvrstiti $\mathrm{v}$ ta ali oni PN, hkrati pa ni neobičajno, če mora sociologija kulture določeno spoznavno prakso proučevati hkrati kot del baze in nadzidave istega $\mathrm{PN}$-ja.

Za konec moramo dodati, da izraz zavest uporabljamo v sociološkem, ne v psihološkem smislu. Ideologija, pa naj gre za praktično zavest ali oblike družbene zavesti, je v veliki meri nezavedna, delovanje, ki ne temelji na zavesti o svoji družbeni določenosti (prim. problematiko blagovnega fetišizma), pa je v psihološkem smislu zavestno delovanje. Prav tako je treba dodati, da naša tukajšnja koncepcija družbenih instanc ni popolna. Z »vsebinskega« stališča v okviru marksistične tradicije govorimo o treh instancah: ekonomski, politični in ideološki (Althusser, 1971, 145), kar ustreza Marxovi bazi, pravnopolitični nadzidavi in oblikam družbene zavesti (če pustimo ob strani teoretsko/znanstveno prakso). Brez vključitve politične instance (kot posebne vrste prakse, ki ni ne materialna ne spoznavna, ampak preoblikuje družbena razmerja) je koncepcija vsekakor nepopolna. A ker sociologije kulture ne zadeva neposredno, lahko ta problem počaka na kako drugo priložnost.

\section{Literatura}

Altise, L. [Althusser, L.], O materialističkoj dialektici, v: Altise, L., Za Marxa, Beograd 1971, str. 139-199.

Althusser, L., Ideologija in ideološki aparati države, v: Althusser, L., Izbrani spisi, Ljubljana 2000, str. 53-110.

Althusser, L., Balibar, É., Reading Capital, New York, London 2006.

Godelier, M., Rationality and Irrationality in Economics, New York 1972.

Kerševan, M., Religija kot družbeni pojav, Ljubljana 1975.

Kerševan, M., Razredna analiza in marksistična družbena teorija, Ljubljana 1980.

Kržan, M., V. N. Vološinov in teorija dejavne govorice, v: Vološinov, V. N., Marksizem in filozofija jezika, Ljubljana 2008, str. 223-247.

Lévi-Strauss, C., Uvod v delo Marcela Maussa, v: Mauss, M., Esej o daru in drugi spisi, Ljubljana 1996, str. 227-266. 
Marx, K., Engels, F., Nemška ideologija, v: Marx, K., Engels, F., Izbrana dela, 2. zvezek, Ljubljana 1979, str. 5-352.

Marx, K., Kapital. Kritika politične ekonomije, 1. zvezek, Ljubljana 1986.

Marx, K., H kritiki politične ekonomije 1858-1861, Ljubljana 1989.

Merton, R. K., Social Theory and Structure, New York 1968.

Močnik, R., Marcel Mauss, klasik humanistike, v: Mauss, M., Esej o daru in drugi spisi, Ljubljana 1996, str. 267-303.

Parsons, T., Essays in Sociological Theory, New York 1964.

Shaikh, A., Tonak, E., Measuring the Wealth of Nations, Cambridge 1994.

Williams, R., Marxism and Literature, Oxford 1977. 
Marko Kržan

\section{The scientific object of the sociology of culture}

Keywords: the sociology of culture, Marxism, ideology, mode of production

This article outlines the scientific object of the sociology of culture. The starting points are two intuitive objects of this discipline: the cultural sphere as it presents itself to naïve observation, and the methodologically motivated notion that culture/ consciousness is the constitutive aspect of all social phenomena. The article attempts to produce a dialectical synthesis of these opposing positions. It starts with Marcel Mauss's "total social fact," the notion that every social fact is a unity of structure and representation. However, to explain the "cultural" phenomena, the sociology of culture must be able to grasp the specificity of those total social facts that also function as representations in relation to other, "non-cultural" social facts. Such ideological practices or forms of consciousness are its true object. The article goes on to establish the criteria for classifying the ideological and the material social facts as parts of the Marxian base or superstructure. It argues that the formal criterion - type of social relations - is necessary and sufficient for determining to which mode of production a certain material practice belongs. The formal criterion, though, is not sufficient when it comes to ideological practices: from the formal viewpoint, many ideological practices belong to the base of the capitalist mode of production. However, because of their function, they must also be analysed as parts of its superstructure. 